\title{
GESTÃO DAS INSPEÇÕES NA OPERAÇÃO DA USINA DE ITAIPU BINACIONAL
}

\author{
Claudio Augusto Gomes Silva Mota \\ Itaipu Binacional \\ Foz do Iguaçu - Paraná - Brasil \\ cmota@itaipu.gov.br \\ Paulo Zanelli Junior \\ Itaipu Binacional \\ Foz do Iguaçu - Paraná - Brasil \\ zanelli@itaipu.gov.br \\ Marcio Roberto Kriger Lino \\ Itaipu Binacional \\ Foz do Iguaçu - Paraná - Brasil \\ mlino@itaipu.gov.br \\ Ivan Miguel Arzamendia Escobar \\ Itaipu Binacional \\ Ciudad del Este - Alto Paraná - Paraguay \\ arzamen@itaipu.gov.py

\section{Carlos Hernan Mieres Zacarias} \\ Itaipu Binacional \\ Ciudad del Este - Alto Paraná - Paraguay \\ chmieres@itaipu.gov.py
}

\section{RESUMO}

A segurança operacional do setor elétrico brasileiro depende, em última análise, da eficácia na realização de todo o conjunto de ações operacionais necessárias nas mais diversas instalações elétricas brasileiras. Dentro desse contexto, as inspeções efetuadas em equipamentos tanto pelas equipes de operação quanto pelas equipes de manutenção de uma determinada empresa, auxiliam na identificação de anomalias em estado incipiente.

A identificação de anomalias ainda em condição precoce de evolução traz uma série de benefícios ao processo de manutenção e resolução da condição anômala, tais como: redução do dano ao processo industrial envolvido, redução dos custos de manutenção necessários para resolução da anomalia, possibilidade de planejamento da intervenção para um momento que tenha menos impacto sobre a produção industrial, dentre outros.

O presente trabalho visa apresentar a inspeção realizada pelas equipes de operação da Usina Hidrelétrica de Itaipu em toda a instalação. Essa inspeção operativa, atualmente, é realizada de forma presencial com uso de ferramentas computacionais de gestão (o Gerenciador de Inspeções da Operação - GIO). O modo de realização da inspeção operativa em Itaipu Binacional bem como os resultados obtidos também serão comentados.

Palavra-chave: Segurança Operacional; Inspeção Operativa; Gestão de Inspeções; Ferramentas Computacionais; Usinas Hidrelétricas. 


\begin{abstract}
The operational safety of the national power system ultimately depends on the effectiveness in carrying out the full set of operational actions required at the most diverse brazilian electrical installations. Within this context, equipment inspections by both the operating and maintenance teams of a given company help identify incipient anomalies.

The identification of anomalies still in an early condition of evolution brings a great number of benefits to the process of maintenance and resolution of the anomalous condition, such as: reduction of damage to the involved industrial process, reduction of maintenance costs required to solve the anomaly, possibility of planning intervention for a period that has less impact on industrial production, among others.

This paper presents the inspection performed by the operation teams of the Itaipu Hydroelectric Power Plant throughout the facility. This operative inspection is currently performed in person using computational management tools (the Operation Inspection Manager - GIO). The way of performing the operative inspection in Itaipu Binacional as well as the results obtained through this inspection will also be presented in this paper.
\end{abstract}

Keywords: Operational Safety; Operative Inspection; Inspection Management; Computational Management Tools; Hydroelectric Power Plant.

\title{
Como Citar:
}

MOTA, Claudio Augusto Gomes Silva et al. Gestão das inspeções na operação da usina de itaipu binacional. In: SIMPÓSIO DE PESQUISA OPERACIONAL E LOGÍSTICA DA MARINHA, 19., 2019, Rio de Janeiro, RJ. Anais [...]. Rio de Janeiro: Centro de Análises de Sistemas Navais, 2019.

\section{ITAIPU BINACIONAL}

\subsection{APRESEnTAÇÃo}

A Itaipu Binacional é uma empresa de geração de energia elétrica cujo objetivo, quando de sua criação, é operar e manter a maior usina hidrelétrica em geração de energia do mundo, a Usina Hidrelétrica de Itaipu. A Usina Hidrelétrica de Itaipu, localizada no Rio Paraná próximo a foz do Rio Iguaçu, possui capacidade instalada de 14.000MW distribuídos em 20 unidades geradoras de potência de 700MW cada.

A Itaipu Binacional é uma empresa pertencente aos governos brasileiro e paraguaio atendendo, dessa forma, ambos os países. Em 2018, por exemplo, a Usina Hidrelétrica de Itaipu foi responsável pelo atendimento de 14,6\% da energia elétrica consumida no Brasil e de $90,7 \%$ do consumo de energia elétrica do Paraguai [1]. Tais números refletem a importância estratégica da usina para a economia dos dois países.

Devido ao tempo em operação da Usina Hidrelétrica de Itaipu, têm sido conduzidos processos pontuais de modernização tecnológica em equipamentos/processos vinculados a instalação. Tais processos visam preparar a usina para a atualização tecnológica das unidades geradoras planejada para ter início nos próximos dois anos.

\subsection{OPERAÇÃo dA USINA HIDRELÉTRICA DE ITAIPU}

O Departamento de Operação da Usina é a unidade funcional responsável pela coordenação da execução da operação de todos os equipamentos da Usina Hidrelétrica de Itaipu. Além disso, esta equipe possui a incumbência de efetuar as inspeções operacionais diárias 
nos equipamentos da instalação bem como reportar o resultado dessas inspeções às respectivas equipes de manutenção [2].

As equipes de Operação da Usina são dividas, de forma mais básica, em equipes de atendimento em horário comercial e equipes em turno de revezamento. As equipes de turno de revezamento, compostas por 12 operadores por turno, trabalham em turnos de seis horas fazendo com que a presença desses profissionais na instalação seja ininterrupta.

Dentre as atribuições dos operadores de turno de revezamento, destacam-se: (a) os processos de partida/parada de unidades geradoras, (b) energização de linhas, barramentos e transformadores, (c) análise, isolação e acompanhamento da execução de trabalhos de manutenção ou obras na área da usina, (d) execução de inspeções operacionais e (e) supervisão dos ativos de geração e transmissão de Itaipu Binacional para pleno atendimento aos sistemas elé-tricos atendidos - brasileiro e paraguaio.

\subsection{ESTRUTURAÇÃO dAS EQUIPES DE OPERAÇÃo PARA EXECUÇão dAS INSPEÇÕES}

A Figura 1 apresenta a organização simplificada do Departamento de Operação da Usina e Subestações - OPU.DT. Dentro desse departamento são planejadas e executadas as inspeções operacionais.

O Departamento de Operação da Usina e Subestações - OPU.DT - é dividido em duas divisões denominadas OPUE.DT (Divisão de Estudos, Normas, Programação e Estatística da Operação de Usina) e OPUO.DT (Divisão de Operação da Usina e Subestações).

As competências desses setores sobre as inspeções operacionais são as seguintes: a OPUE.DT, através do setor SOEN, possui a função da elaboração e gestão das Planilhas de Inspeções da Operação (PIO) e a OPUO.DT possui a função de executar as inspeções operacionais conforme estabelecido nas planilhas. A divisão dessas atribuições pode ser visualizada na Figura 1, a seguir.

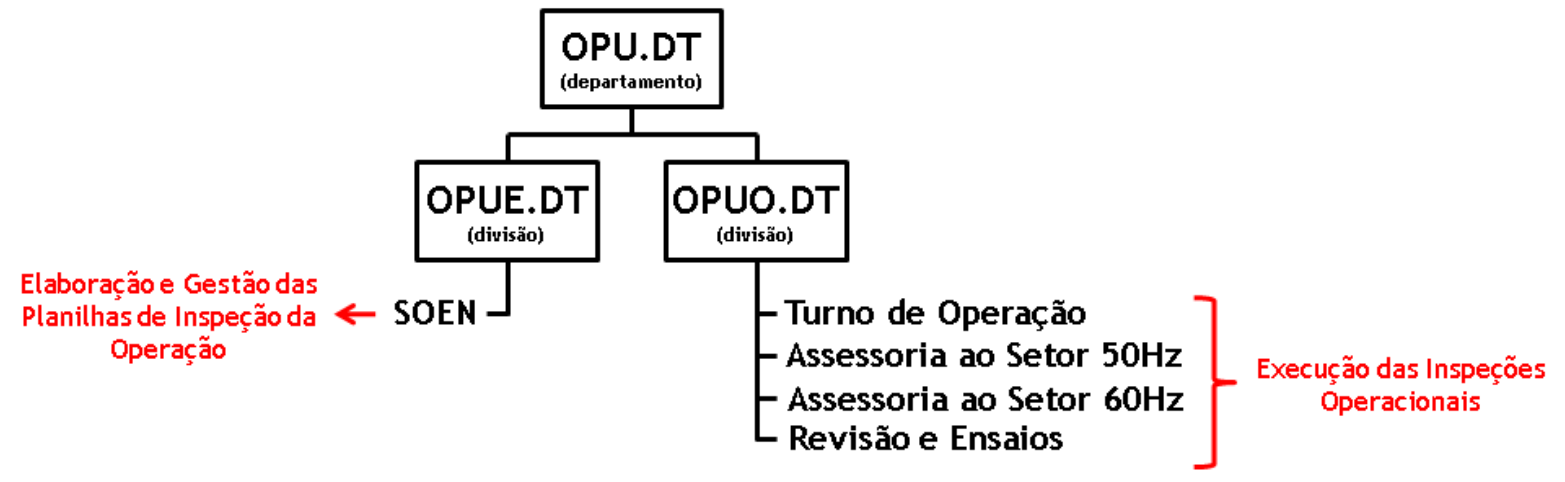

Figura 2 - Organização simplificada do Departamento de Operação da Usina e Subestações

\section{INSPEÇÕS OPERACIONAIS}

Como descrito anteriormente, dentre todas as atribuições dos operadores de turno de revezamento, a inspeção ope-racional encontra papel de destaque. A inspeção operacional, por definição, é toda verificação sistemática no desempenho de equipamentos e das áreas de operação, avaliada por inspeção humana local usando a experiência do operador e recursos tecnológicos auxiliares [3].

Nas inspeções operacionais são observados quaisquer aspectos que fujam à normalidade operacional dos equipamentos e/ou áreas de operação. Essa verificação antecipada permite a antecipação de ações corretivas minimizando os impactos que a evolução dessas anor- 
malidades poderiam provocar e o custo relacionado à intervenção das equipes de manutenção.

A adoção e sistematização de um sistema para gestão das inspeções operacionais, em Itaipu Binacional, está alinhada com o Objetivo Estratégico 1 da empresa, a saber, "garantir a segurança da produção de energia com os melhores índices de qualidade” [4]. Nas inspeções operacionais são verificados aspectos como:

(a) Ruídos anormais em equipamentos;

(b) Vibração excessiva de um equipamento;

(c) Níveis de óleo em sistemas hidráulicos;

(d) Valores de temperatura de óleo em sistemas e de metal em mancais;

(e) Fluxos de água através de tubulações essenciais ou de drenos de filtros;

(f) Rachaduras em estruturas civis;

(g) Odores;

(h) Desajustes ou danos em dispositivos de controle, proteção ou supervisão; e

(i) Condições que possam acarretar risco à segurança das pessoas ou da instalação.

A grande maioria das inspeções operacionais executadas pelas equipes de operação em Itaipu Binacional tem caráter rotineiro e periodicidade definida. A periodicidade pode levar em conta fatores sazonais e ser alterada de acordo com modificações nas condições do meio ambiente em torno de equipamento/sistema ou devido a alguma anormalidade observada durante inspeções anteriores onde se deseje um acompanhamento específico mais frequente.

\subsection{SISTEMA GERENCIADOR DAS INSPEÇÕES DA OPERAÇÃO - GIO}

Com o objetivo de padronizar e organizar as inspeções operacionais realizadas pelas equipes de Operação da Usina Hidrelétrica de Itaipu, em 2000, foi instituído um sistema para a realização da gestão dessas inspeções. Dessa forma, teve-se a origem do Gerenciador das Inspeções da Operação - o sistema GIO.

O sistema GIO estabeleceu as planilhas de inspeção da operação (PIO), os mapas contendo as rotas que os operadores deveriam percorrer para a verificação dos equipamentos associados a cada uma das planilhas e um software para delegação e registro individual da execução das inspeções operacionais.

Com a adoção dessa ferramenta computacional, foram observados ganhos substanciais tanto na qualidade das inspeções operacionais realizadas quanto na quantidade de anomalias encontrada mediante a inspeção das equipes de operação. Somente no primeiro ano após a aplicação da ferramenta, o número total de anomalias encontradas cresceu 31,5\% e o de anomalias caracterizadas como alto impacto (afetam diretamente a produção de energia elétrica) subiram 38,7\%.

Finalmente, esse sistema permitiu, também, a gestão das inspeções operacionais fornecendo ao gestor as informações necessárias para a contínua melhora das inspeções realizadas.

\subsection{GERENCIADOR DAS INSPEÇõES DA OPERAÇÃO E COLETA DE DADOS DAS INSPEÇÕES - GIO/CDI}

Durante anos foram consideradas propostas para a melhoria do sistema GIO em termos de desempenho e de mobilidade. Essas melhorias visavam, também, mitigar determinados problemas observados na versão computacional anterior. Assim, em 2014, foi 
colocado em produção.

Dessa forma, foram adquiridos tablets com leitores de código de barras para a modernização da inspeção operacional. Foram instalados nas áreas de inspeção cadastradas no sistema placas de identificação da área com o relativo código de barras gravado. A inspeção, atualmente, como demonstra a Figura 3, é realizada pelo operador através da leitura da placa de identificação com código de barra referente ao local de inspeção.
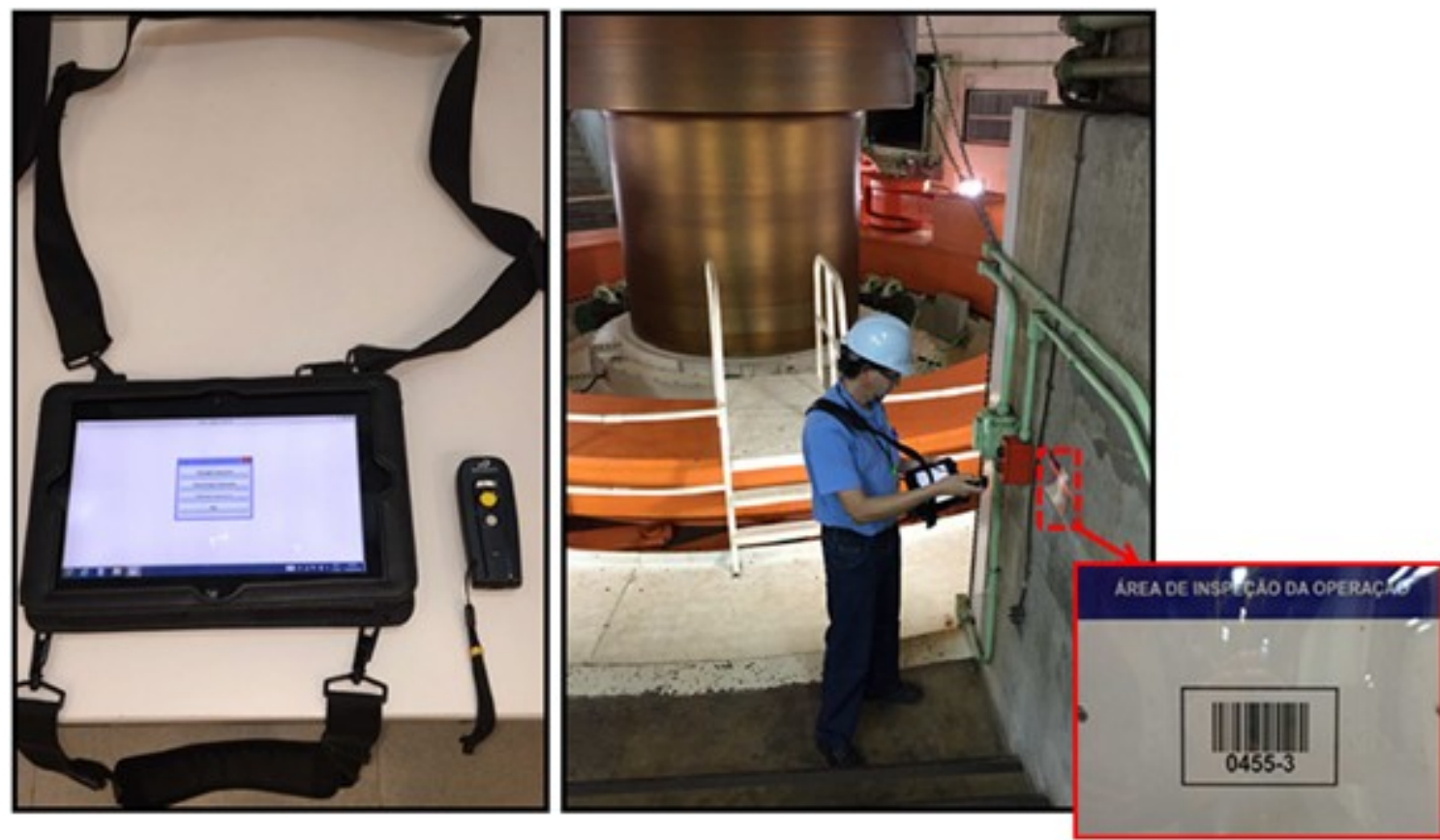

Figura 3 - Inspeção operacional com o uso de tablet e código de barra relativo a área de inspeção

\subsubsection{Definição das inspeções agendadas}

Inicialmente, quando da configuração e cadastramento das Planilhas de Inspeção da Operação, fica estabelecido pelo OPUE.DT o agendamento das inspeções operacionais (quantidade de vezes que a inspeção será executada, em quais dias da semana, que equipe executará, quais os parâmetros devem ser observados, dentre outros).

No dia da semana determinado para a execução da inspeção, os supervisores são responsáveis por definir no GIO quais os operadores que serão responsáveis pela execução das inspeções agendadas. A Figura 3, apresentada a seguir, demonstra o processo de delegação da inspeção operacional executado pelo supervisor de equipe para os operadores sob sua supervisão. 


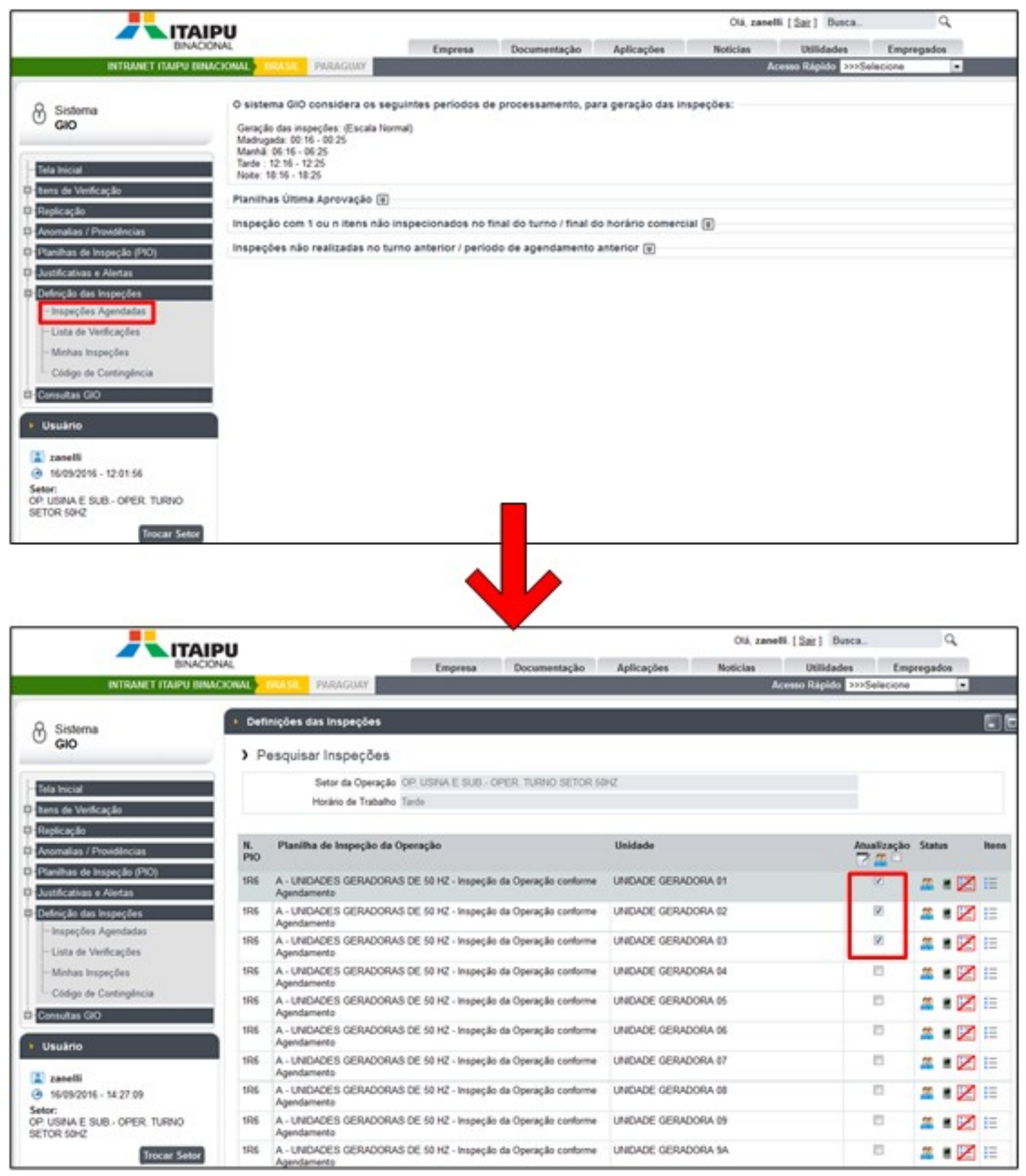

Figura 4 - Procedimento para atribuição de inspeções operacionais

Nessa tela inicial, portanto, o supervisor tem a sua disposição todas as PIO disponíveis e realiza a seleção da PIO programada e a definição do operador responsável pela execução da inspeção operacional selecionada.

\subsubsection{Carregamento de inspeções para o sistema CDI (tablet)}

Após o supervisor realizar a delegação da inspeção operacional para determinado operador, o operador selecionado, no tablet, deve carregar as inspeções relativas a ele no sistema CDI. Para realizar essa tarefa, o operador deve efetuar login no sistema CDI (tablet) e carregar as inspeções operacionais reservadas para ele. A Figura 4 apresenta esse passo. 


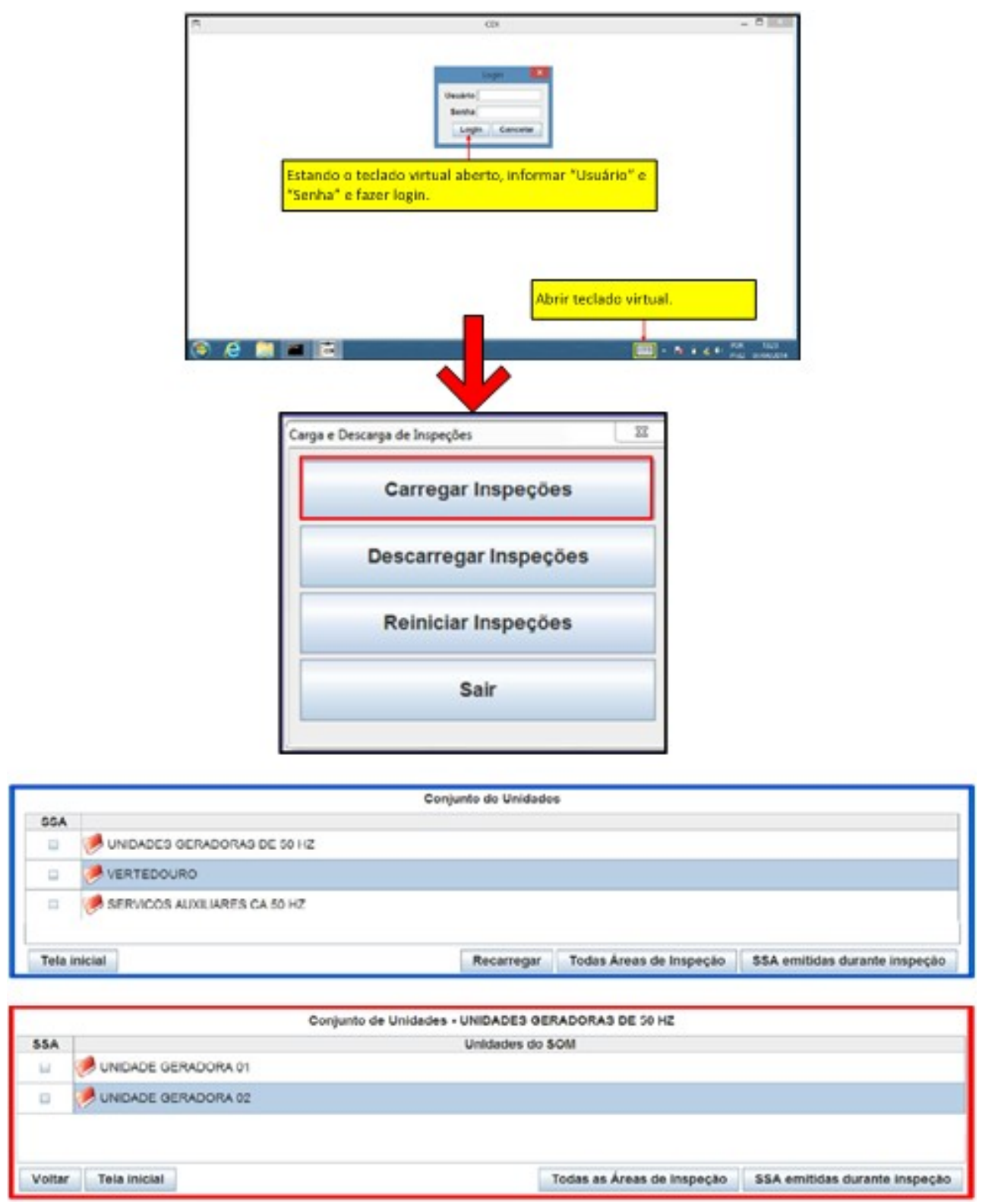

Figura 5 - Procedimentos realizados para o carregamento e seleção da inspeção operacional

Após o término da operação de carregamento das inspeções no sistema CDI (tablet), o operador deve selecionar o conjunto de unidades de equipamentos onde iniciará a sua inspeção conforme apresentado na caixa em vermelho na Figura 05 acima. Após selecionar o conjunto desejado, uma relação de todas as áreas de inspeções cadastradas no sistema para aquele conjunto de equipamentos será apresentado na tela. As áreas de inspeção são localizações físicas onde estão instalados os equipamentos que serão inspecionados e possuem uma placa contendo um código de barras que o operador executor deve passar o leitor de código de barras. A Figura 6 apresenta o código de barras em determinada área de inspeção. 


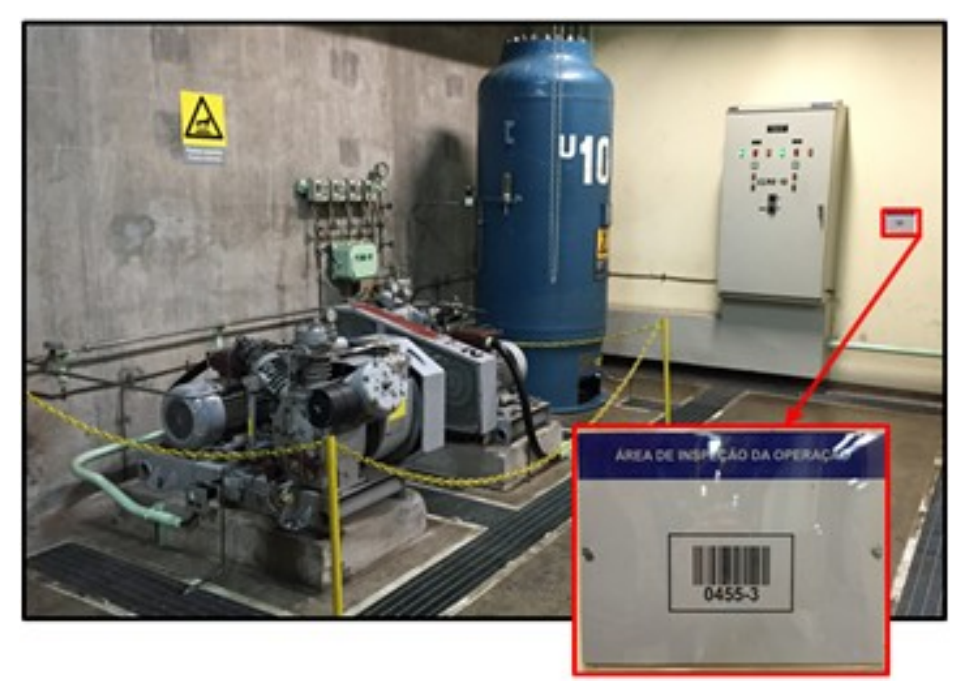

Figura 6 - Placa com código de barras em determinada Área de Inspeção

Dessa forma, o operador executor da inspeção operacional pode se deslocar até o local e efetuar a leitura do código de barras disposto na área de inspeção selecionada. Após a leitura do código de barras, surge na tela do tablet os Itens de Verificação que o operador executor deverá inspecionar. As áreas de inspeção apresentadas no sistema CDI quando da seleção do conjunto bem como os Itens de Verificação dispostos ao operador executor podem ser visualizados na Figura 7.
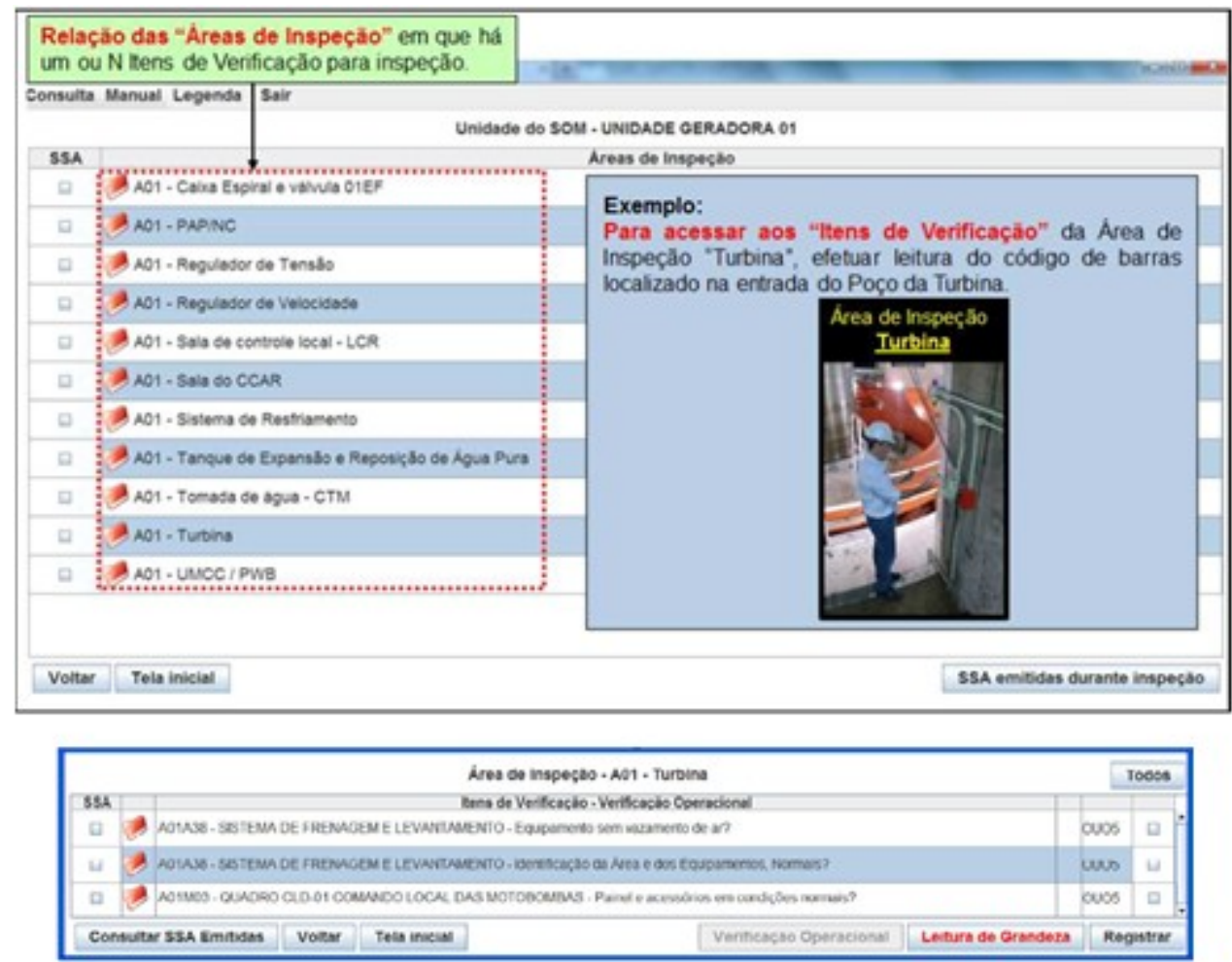

Figura 7 - Áreas de Inspeção e Itens de Verificação

\subsubsection{Tipos de Itens de Verificação}

No sistema GIO/CDI estão cadastrados dois tipos de Itens de Verificação, são eles: (a) verificação operacional e (b) leitura de grandeza operacional. Ambos os itens de verificação estão apresentados na figura a seguir. 

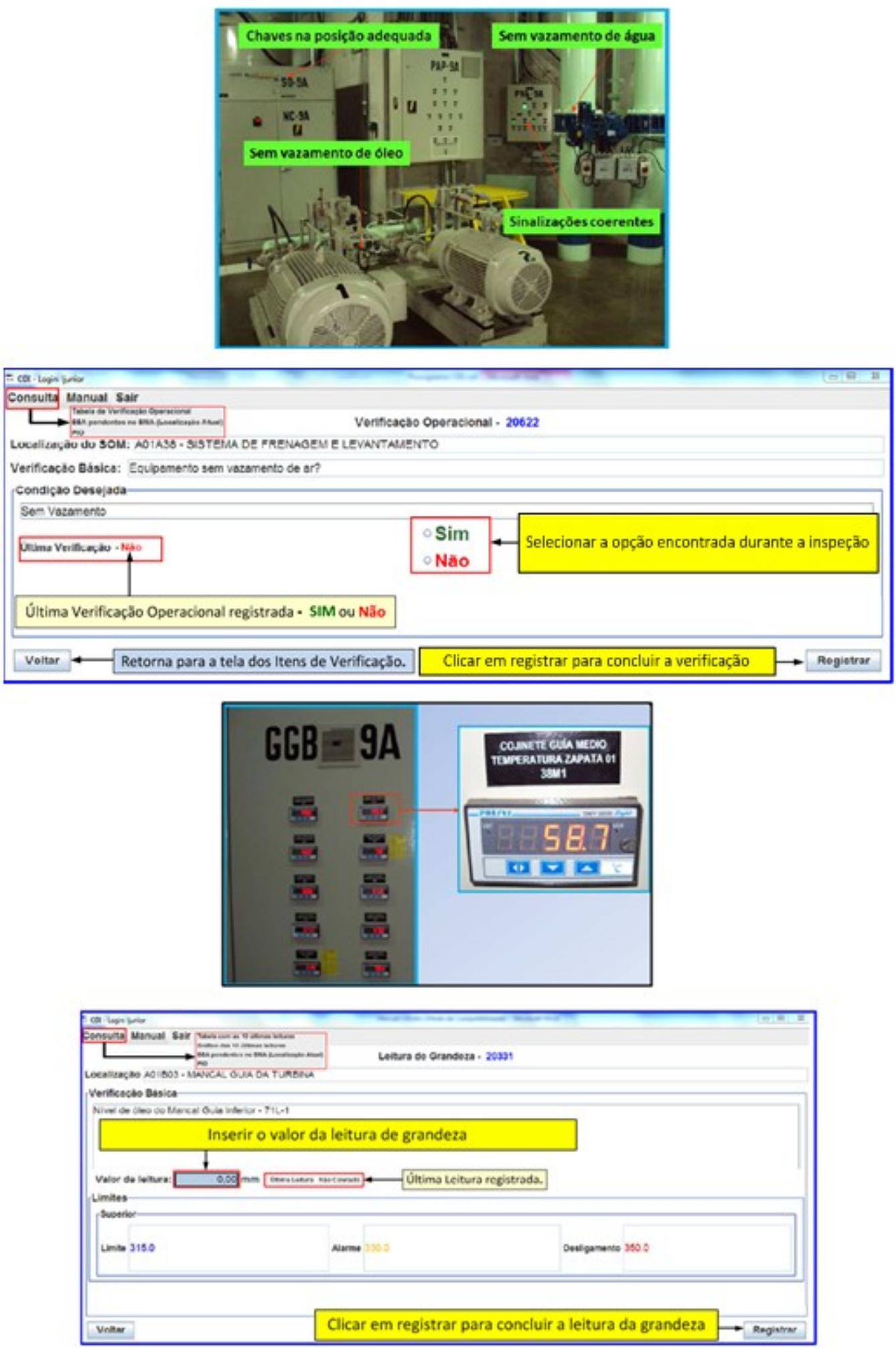

Figura 8 - Verificação Operacional e Leitura de Grandeza Operacional

A diferença entre os dois tipos de Itens de Verificação está no fato de que a Verificação Operacional nada mais é que a verificação de uma condição de determinado equipamentos (existência de vazamento, posição de chave, sinalizações coerentes, dentre outros). A Leitura de Grandeza Operacional, por sua vez, é a inserção de determinado valor numérico (nível de óleo, fluxo de água, temperatura de mancal, dentre outros).

O procedimento de registo dos dois tipos de itens de verificação também está 
apresentado na figura anterior.

\subsubsection{Código de Contingência}

O sistema GIO/CDI gera automaticamente, quando determinada inspeção operacional é gerada, um Código de Contingência. Caso haja qualquer anormalidade que impeça a correta leitura do código de barras da placa identificadora da Área de Inspeção, o operador executor solicita ao supervisor o Código de Contingência.

Após receber o Código de Contingência, o operador executor cadastra este código informando a anormalidade que impediu a correta leitura do código de barras. Após essa operação, todos os supervisores e gerentes cadastrados recebem um e-mail informando a anormalidade ocorrida.

\subsubsection{Anomalia Operacional}

No tocante a inspeção realizada pelas equipes de operação de Itaipu Binacional, é considerada uma anomalia operacional qualquer aspecto observado na Inspeção Operacional que fuja à normalidade operacional dos equipamentos e/ou áreas de Operação. As anomalias operacionais são classificadas como: (a) alto impacto, (b) médio impacto e (c) baixo impacto.

Essa classificação foi elaborada com base no histórico de emissão de SSA levando em consideração o impacto que seria causado a produção de energia elétrica se a anomalia não houvesse sido descoberta em fase incipiente. A Figura 9, por exemplo, ilustra sete anomalias típicas e a sua classificação. Atualmente, no total, existem 54 anomalias vigentes cadastradas.

\begin{tabular}{|l|l|l|l|}
\hline Anomalia: & & \\
\hline Consulta & Nivel de Impacto & Vigente \\
\hline Código & Descrição & Alto & Sim \\
\hline 55 & AFETA FUNCIONAMENTO DA PROTECAO OU CONTROLE & Medio & Sim \\
\hline 34 & AGUA / UMIDADE EXCESSIVA EM EQUIPAMENTO & Medio & Sim \\
\hline 58 & ANORMALIDADE EM PONTO DE SISTEMA DIGIAL & Medio & Sim \\
\hline 59 & ANORIMALIDADE NO SISTEMA DE FREIOS & Baixo & Sim \\
\hline 01 & ANTI-INCENDIO - DEFEITO QUE NAO AFETA A OPERACIONALIDADE & Sim \\
\hline 65 & ANUNCIADORIINDICADOR DE ESTADO COM DEFEITO & Baixo \\
\hline
\end{tabular}

Figura 9 - Anomalias cadastradas no GIO/CDI

No momento da detecção de uma anomalia operacional, o operador executor toma todas as medidas cabíveis, informando a sua supervisão e acionando, quando necessário, as equipes de manutenção para atendimento da anomalia. A atuação sobre uma anomalia identificada em inspeção permite a antecipação de ações corretivas, minimizando o impacto que a evolução da falha poderia vir a causar sobre a produção de energia elétrica.

Além disso, a detecção de uma falha incipiente contribui para a melhoria dos índices associados à produção de energia elétrica, tais como: indisponibilidade forçada, falhas na partida e parada de unidades geradoras, diminuição do impacto ambiental e 
melhora na performance e aumento da vida útil dos ativos da empresa.

Caso, durante uma inspeção operacional seja detectada determinada anomalia, o GIO/CDI induz o operador executor a registrar essa anomalia para que as equipes de manutenção de determinado equipamento sejam informadas.

\subsubsection{Descarregamento das inspeções executadas no sistema CDI}

Finalmente, após a execução das inspeções operacionais, o operador executor deve descarregar as inspeções. Ao término do processo de descarregamento a obrigação do operador para com as inspeções operacionais realizadas está finalizada. O processo de descarregamento de inspeções está ilustrado na Figura 10.

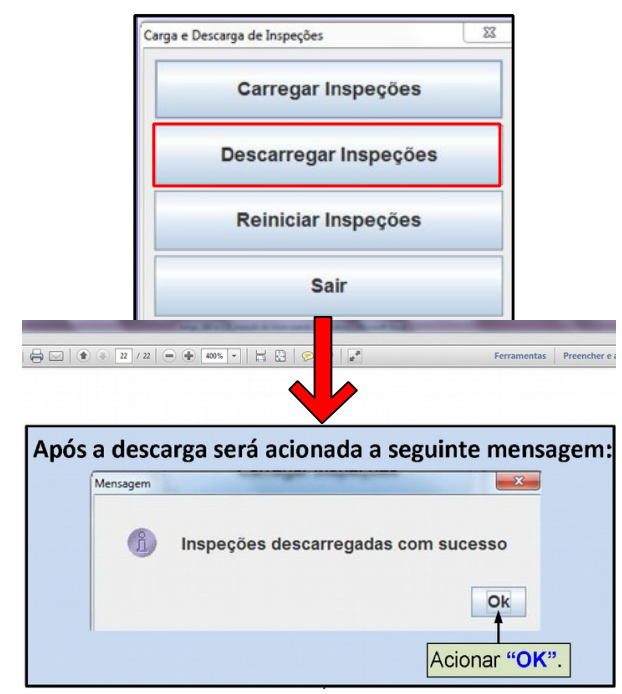

Figura 10 - Descarregamento de inspeções operacionais

\section{RESULTADOS APRESENTADOS NO SISTEMA GIO/CDI}

Como descrito anteriormente, a inserção do sistema GIO/CDI acarretou em diversas melhorias no processo de inspeção operacional. Dentre os principais resultados fornecidos pelo sistema GIO/CDI tem-se: (a) a possibilidade de análise de desempenho de operador, (b) a consulta ao gráfico de leituras e (c) a consulta estatísticas das inspeções.

\subsubsection{Análise do Desempenho dos Operadores Executores}

No sistema GIO é possível verificar o desempenho individual em inspeções de todos os operadores executores. Esse desempenho é dado através de um índice obtido diretamente no sistema GIO/CDI a partir da equação [1], descrita abaixo:

$$
A P I=(A A I \times \text { peso } A+A M I \times \text { peso } B+A B I \times \text { peso } C) \times\left(1-\left(\frac{N R}{T I}\right)\right)^{2}
$$

Onde:

API: Análise por Inspeção;

AAI: Anomalias de Alto Impacto;

Peso A: peso dado às anomalias de alto impacto;

AMI: Anomalias de Médio Impacto;

Peso B: peso dado às anomalias de médio impacto;

ABI: Anomalias de Baixo Impacto; 
Peso C: peso dado às anomalias de baixo impacto;

AAI: Anomalias de Alto Impacto;

INR: total de itens de verificação definidos para o operador executor, não inspecionados e não justificados.

TI: total de itens de verificação definidos para o operador executor.

Os pesos A, B e C foram definidos pelos supervisores da operação como sendo 15, 5 e 1, respectivamente. Para a obtenção do desempenho do operador executor, o supervisor acessa o sistema GIO e retira essa informação. É possível, inclusive, a criação de um ranking com o desempenho de vários operadores e assim comparar o desempenho em execução de inspeção entre eles.

\subsubsection{Consulta de Gráficos de Leitura}

No sistema GIO é possível, também, verificar o comportamento gráfico de um ou mais Leituras de Grandeza Operacionais em determinado período de tempo. A Figura 11 apresenta, por exemplo, um relatório criado automaticamente para a variação do nível de água pura no tanque de expansão da unidade geradora 7 de Itaipu Binacional entre os dias 01.09.2016 e 09.09.2016.

\subsubsection{Consulta da Estatística das Inspeções}

Finalmente, o sistema permite a consulta de diversas estatísticas ligadas as inspeções operacionais. Estatísticas tais como: (a) data e hora da inspeção, (b) número da inspeção, (c) tempo gasto para a execução da inspeção pelo operador executor, (d) itens de verificação inspecionados e não inspecionados, (e) nome do operador responsável pela inspeção operacional, (f) setor responsável pela inspeção operacional, (g) turno de operação responsável pela inspeção operacional, (h) status da inspeção operacional e (i) número de anomalias totais detectadas durante inspeções operacionais.

Um banco de dados com todas essas informações sobre as atividades de inspeção operacional em Itaipu Binacional se configura em uma excelente ferramenta de gestão de equipe permitindo, por exemplo, o planejamento de treinamentos sobre equipamentos e/ou sistemas, distribuição equivalente dos itens a serem inspecionados entre as equipes de operação, premiação aos operadores executores com os maiores índices de desempenho em inspeções operacionais, dentre outras possibilidades.

Somada a possibilidade de extração de dados do sistema GIO/CDI, podem ser utilizados softwares especializados em manipulação de banco de dados ou business Inteligence, (o Tableau, por exemplo) permitindo construir gráficos informativos sobre praticamente todas as informações que são externadas pelo sistema GIO/CDI.

\section{RESULTADOS DAS INSPEÇÕES OPERACIONAIS}

Com o advento do sistema GIO/CDI foi observado um aumento substancial nos números de itens inspecionados durante as inspeções operacionais realizadas pelos operadores executores em Itaipu Binacional. 


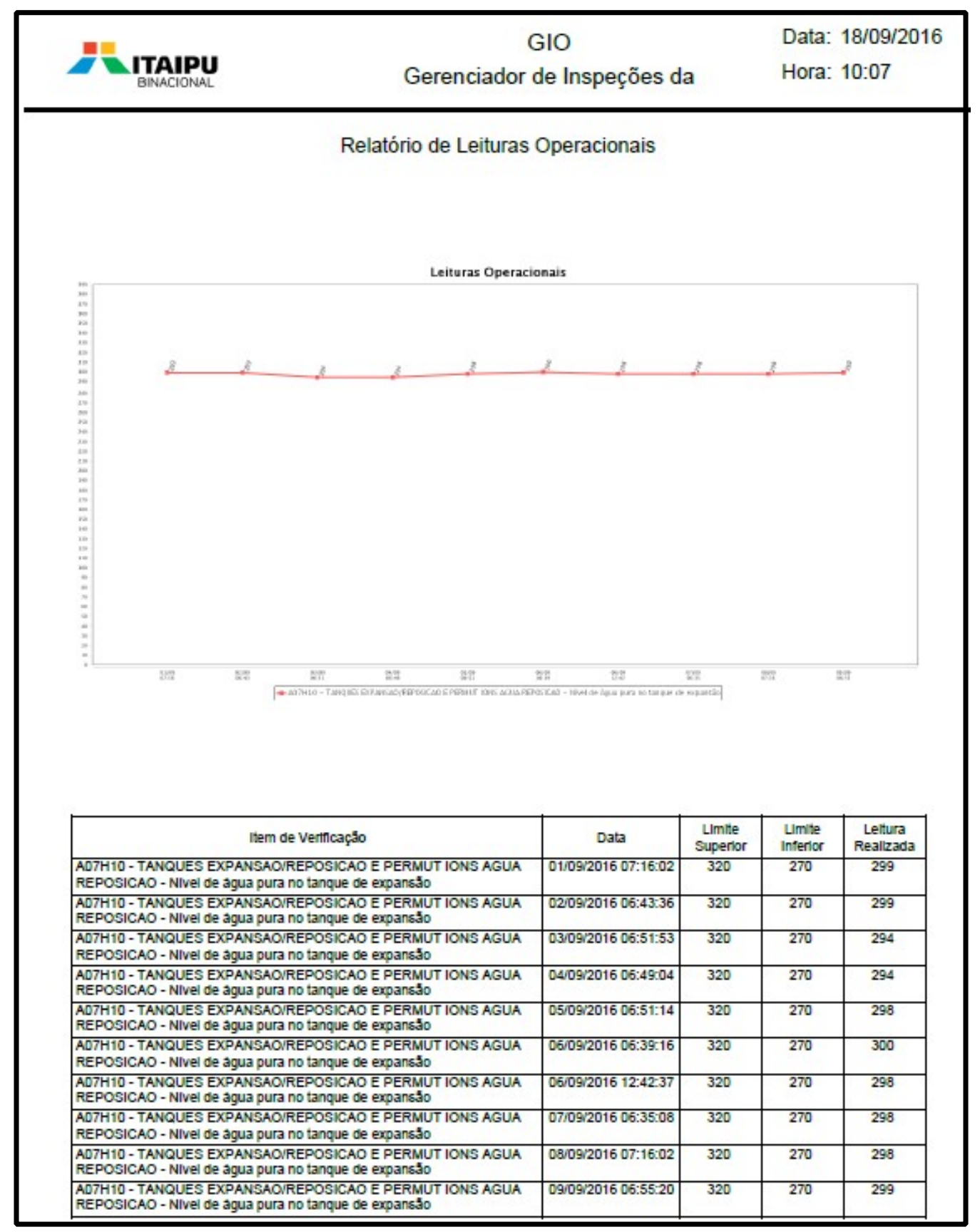

Figura 11 - Relatório do nível de água pura no tanque de expansão da unidade geradora 7

Atualmente, em Itaipu Binacional, são inspecionados mensalmente aproximadamente 368.000 itens de verificação distribuídos em mais de 30.000 inspeções realizadas pelos operadores executores das equipes de operação. Esses dados, para o mês de abril de 2019, estão apresentados na Figura 12.

Essas inspeções contribuem diretamente para os recordes de geração que têm sido estabelecidos nos últimos anos, pois permitem que danos que acarretariam manutenções corretivas sejam identificados de forma incipiente e resolvidos em manutenções programadas em momentos em que os sistemas elétricos interligados não sejam grandemente afetados.

Por fim, através de uma interligação entre o sistema GIO/CDI e o software de banco de dados Tableau, tem sido possível a criação de telas de supervisão para os supervisores da 
operação terem uma gestão das inspeções operacionais mais facilitada. Através de dados em tempo real colhidos pelo Tableau no sistema GIO/CDI, o supervisor de operação conta com um dashboard apresentando as informações mais relevantes sobre o processo de execução das inspeções operacionais. Esse dashboard pode ser visualizado na Figura 13.

\section{Itens e inspecões abril de 2019}

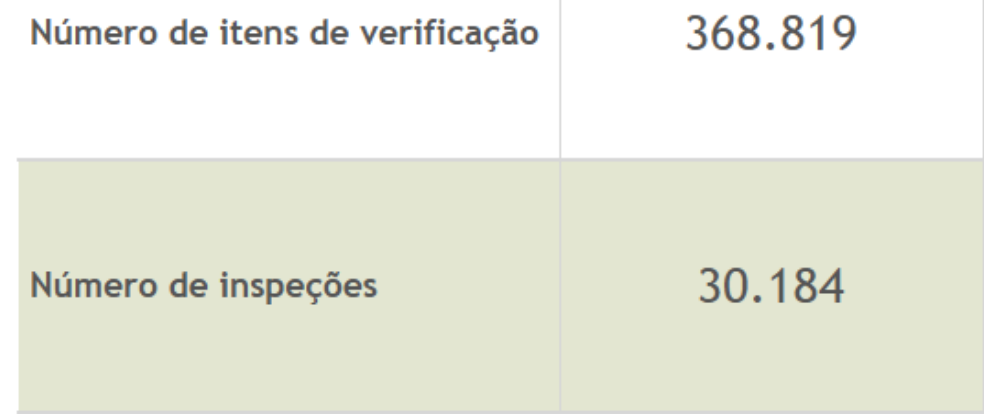

Figura 12 - Inspeções e itens de verificação inspecionados em abril de 2019.

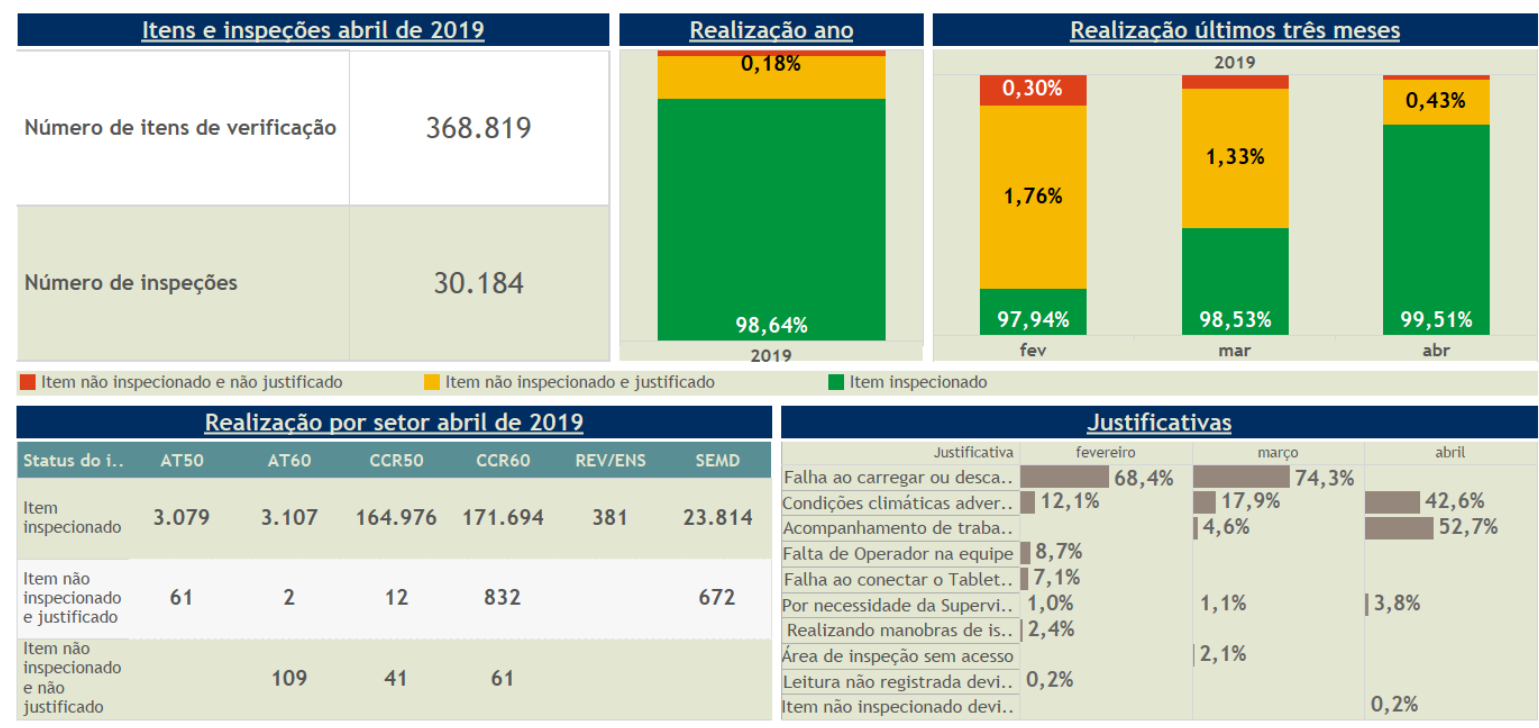

Figura 13 - Dashboard de supervisão com informações do sistema GIO/CDI a partir do software Tableau.

Nesse dashboard podem ser visualizadas informações a respeito dos índices de execução das inspeções anual, dos índices obtidos por cada um dos setores executores, das porcentagens de execução, não execução e justificação das inspeções operacionais bem como as causas das justificativas cadastradas pelos operadores executores.

\section{CONCLUSÃO}

Após pouco mais de cinco anos do início da utilização do sistema GIO/CDI como ferramentas de planejamento, gestão e execução das inspeções já são claras as melhorias proporcionadas à Operação da Usina Hidrelétrica de Itaipu.

A implementação do sistema GIO/CDI promoveu intensos debates dentro das equipes de operação e, consequentemente, diversas sugestões de melhoria para o processo de inspeção operacional foram debatidas o que acarretou em um enriquecimento técnico 
evidente para todas as partes envolvidas.

As Planilhas de Inspeção de Operação passaram por diversos ajustes que as tornaram mais aderentes a realidade da execução. Outro recurso do sistema GIO/CDI que vem sendo utilizado com frequência é a utilização das leituras de grandeza registradas no banco de dados do sistema para plotagem de gráficos visando o acompanhamento das anomalias. Essa ação melhora a qualidade da supervisão e da tomada de decisão das equipes de operação diante de uma condição de anomalia.

Não obstante, foram desenvolvidos, com o software Tableau, cenários que permitem aos gestores da Operação o acompanhamento em tempo real e consulta de todas as informações contidas no banco de dados do GIO. Assim, é possível para o gestor montar um cenário contendo gráficos com as informações que julgar importante para a gestão da equipe sob sua supervisão.

Por fim, a utilização de um índice capaz de representar a eficiência em inspeções de um determinado operador executor diminui a subjetividade do processo de gestão do desempenho do empregado, permitindo ao gestor premiar os melhores inspetores e tomar ações para incentivar aqueles que têm um desempenho abaixo da média do grupo. Dessa forma o grupo de inspetores se tornará homogêneo e executando as inspeções operacionais com maior nível de qualidade.

\section{REFERÊNCIAS BIBLIOGRÁFICAS}

[1]GOMES JUNIOR L. C S.; BASTOS MARTINS M.; CONCEPCIÓN DÁVALOS L. M. e PEREIRA CAVALCANTI F. H.. Gestão de Anomalias: Inspeção da Operação da Itaipu Binacional.

[2]GOMES JUNIOR L. C S.; BERTASI J. D..; e PACHOAL S. E. Manual de Utilização do Sistema CDI.

[3]GOMES JUNIOR L. C S.; LOPEZ OJEDA F. A.; BERTASI J. D..; e PACHOAL S. E. Manual de Utilização do Sistema GIO.

[4]ZANELLI JUNIOR, P; MOTA, C. A.; GIMENEZ, R. A.; BOCH, V.; ESTECHE, A. Novo GIO - Inspeção Operacional com o Uso de Tablets. 